\section{Marcas territoriais do passado autoritário: lugares de memória e de consciência na América Latina}

\author{
Samantha Viz Quadrat [*] \\ [*] Universidade Federal Fluminense (UFF). Niterói \\ (RJ), Brasil. Email: samantha.quadrat@gmail.com
}

ORCID: https://orcid.org/0000-0003-1547-1000

\section{Izabel Pimentel da Silva [**]}

\section{[**] Universidade do Estado do Rio de Janeiro-} Faculdade de Formação de Professores (Uerj-FFP). São Gonçalo (RJ), Brasil. Email: belprisk@hotmail.com

ORCID: https://orcid.org/0000-0003-0991-5322

\begin{abstract}
Resumo: As experiências autoritárias do século XX foram marcadas pelo uso intenso da violência na perseguição aos seus oponentes e/ou a grupos sociais considerados "indesejáveis" às ditaduras, bem como pela tentativa de implementar uma nova narrativa ao país. Para alcançar esses objetivos, personagens, acontecimentos e lugares foram ressignificados. O presente dossiê reúne artigos que analisam essas transformações do espaço público e privado com novas funções e formas de uso. Os artigos aqui apresentados demonstram a amplitude do conceito de "lugares de memória", que não se restringem apenas aos espaços diretamente associados às práticas de violência e tortura das ditaduras, mas contemplam espaços e regiões pouco explorados pela historiografia relacionada ao tema e destacam as disputas de memórias e os embates políticos e sociais envolvidos na identificação e recuperação desses lugares no período democrático e nos usos políticos do passado.
\end{abstract}

Palavras-chave: Ditadura; Lugares de memória e consciência; América Latina.

\section{Territorial marks of an authoritarian past: sites of memory and conscience in Latin America}

\begin{abstract}
The XX century authoritarian experiences were marked by the intensive use of violence in the persecution of their opponents and/or "unwanted" social groups by the dictatorship, as well as the attempt of the implementation of a new narrative to the country. In order to reach its goals, characters, events and sites were reframed. This dossier compiles articles that analyze transformations of the public and private sites and their new functions and use forms. Therefore, the articles here represented show the concept range of the "Sites of Memory" that are not restricted to the ones associated to the practice of violence and torture performed by the dictatorship, they also included sites that were not so well explored by historiography and they highlight the disputes of memory and the political and social clash involved in the identification and recuperation of these sites in the democratic period and in the political use of the past.
\end{abstract}

Keywords: Dictatorship; Sites of memory and conscience; Latin America. 
$\mathrm{D}$ esde as últimas décadas do século XX, mais especificamente a partir da queda do Muro de Berlim, do fim das ditaduras latino-americanas e do apartheid na África do Sul, podemos observar a expansão de políticas de memória em diversos países, cada um com sua temporalidade e suas prioridades. Nesse sentido, como a historiografia recente tem destacado, podemos constatar nas sociedades contemporâneas uma alteração nas relações com o futuro e o passado. O futuro, que era apresentado como o tempo das realizações e da afirmação do progresso, cedeu lugar a um tempo que reservaria maiores possibilidades de certeza e segurança: o passado.

As experiências traumáticas às quais se remetem, mormente a história do tempo presente, têm como uma das suas principais preocupações as ações que dizem respeito à transmissão da memória desses acontecimentos. Como transmitir o horror das experiências ditatoriais para quem não viveu o período? Como abordar um passado sensível com as novas gerações? Como construir o que chamamos de nunca mais em tempos de disputas de narrativas e negacionismos sobre o passado ditatorial? Por trás desse debate podemos identificar três objetivos centrais, a saber: a criação da empatia sobre as vítimas; a condenaçãode qualquer regime ditatorial; e a valorização da democracia e dos direitos humanos.

Para isso, é possível identificar políticas de memória empreendidas por governos comprometidos com essas questões, dentre as quais destacamos o incentivo ao ensino do tema na educação básica; a abertura de processos judiciais para agentes que praticaram graves violações dos direitos humanos; a localização e divulgação de arquivos; recuperação de espaços etc. Na maioria das vezes, essas ações são oriundas das pressões exercidas pela sociedade por meio de grupos de direitos humanos e/ou atingidos direta ou indiretamente pela ação das ditaduras, com o intuito de promover o que chamamos de dever de memória para com as vítimas.

Para o caso do nosso dossiê, a ênfase dos artigos aqui reunidos diz respeito à política de memória relativa a identificação e recuperação de espaços na América Latina onde ocorreram graves violações de direitos humanos ou que foram referências, seja para a resistência ou para a própria ditadura.

Ao falarmos sobre esses espaços, remetemos a dois conceitos-chave para a sua compreensão e que consideramos de fundamental importância destacar nessa apresentação. O historiador Pierre Nora foi o pioneiro nesse debate ao cunhar e consagrar a expressão lugares de memória na historiografia, quando coordenou a coletânea de textos Les lieux de mémoire, editada na França a partir de 1984. Segundo Nora, os lugares de memória nascem e vivem do sentimento de que não existe memória espontânea, que é preciso criar arquivos, que é preciso manter os aniversários, organizar as celebrações, pronunciar as honras fúnebres, estabelecer contratos, porque estas operações não são naturais (Nora, 1993, p. 13). A esse conceito acrescentamos a ideia de que podem ser também lugares de consciência. Segundo a 
International Coalition of Site of Conscience, organização mundial que reúne cerca de duzentos integrantes de mais de cinquenta países, os "sítios de Consciência vão desde os esforços de reestruturação de pequenas comunidades de sobreviventes, aos grandes projetos financiados pelo Estado que visam amplo alcance nacional". Para integrar a coalização, o lugar deverá interpretar a história por meio dos espaços históricos; envolver-se em programas públicos que estimulem o diálogo sobre questões sociais urgentes; promover valores humanitários e democráticos como função principal; e compartilhar oportunidades para a participação pública em questões levantadas no local.

Transformar um lugar de memória em também um lugar de consciência implica identificar, reconhecer e preservar esses espaços. E isso não ocorre sem embates políticos e sociais, disputas de memórias e (re)construções de novos sentidos para o passado e seus usos políticos. Esse processo mobiliza distintos agentes (públicos e privados; individuais, coletivos e/ou institucionais), que passam a atuar como "emprendedores de memória", expressão cunhada por Elizabeth Jelin para designar os atores sociais que criam e executam projetos de memória (com um caráter coletivo) e lutam pela visibilidade de seus empreendimentos, pelo reconhecimento social e pela legitimidade política de suas narrativas do passado (Jelin, 2002, p. 48-49).

Nesse sentido, esses lugares são alvos de intensos debates sobre a sua recuperação, pois alguns ainda são ocupados pelas forças estatais ou são de propriedade privada, como a Casa da Morte, em Petrópolis, Rio de Janeiro. Implica também uma política de patrimônio histórico que reconheça aquele espaço e as ações que ali ocorreram como parte da história oficial do país. A questão do patrimônio vem acompanhada das ações de instituições como a Organização das Nações Unidas para a Educação, a Ciência e a Cultura (Unesco), que os reconhece não apenas como um espaço exclusivo de um drama nacional, mas algo que afeta toda humanidade. Ainda nos casos dos países da América Latina que integram o Mercosul, o Instituto de Políticas Públicas de Direitos Humanos (IPPDH) publicou em 2012 o documento "Princípios fundamentais para as políticas públicas sobre lugares de memória" no qual reconhece a obrigação dos estados participantes em promover ações de caráter pedagógico sobre as ditaduras dos anos 1960 e 1970. Em paralelo e em diálogo com essas duas instituições foram criadas a Rede Sitios de Memoria em America Caribe (Reslac) e a Rede Brasileira de Lugares de Memória (Rebralume).

Além disso, abre-se um intenso debate sobre o que fazer com o espaço. Múltiplas vozes devem ser ouvidas na tentativa de construir um consenso sobre essa ocupação, suas atividades futuras, sobre como deve ser a estatização do horror e como falar sobre os que não estão, os desaparecidos e assassinados etc.

${ }^{1}$ Ver: https://www.sitesofconscience.org 
Tais espaços não devem ser pensados apenas como cenários onde as graves violações de direitos humanos ocorreram, pois, atualmente, são provas judiciais nos processos contra os perpetradores em países como Argentina e Chile. Eles cumprem também um importante papel no ensino do passado recente, não apenas recebendo estudantes, mas promovendo atividades e formação de professores. Por fim, muitas vezes integram o roteiro da secretaria oficial de turismo em diversas cidades. Segundo Teklik e Mesnard (2011, p. 101), o turismo de memória apresenta como elemento central o valor ético de resgate do passado. Lugares como Auschwitz e Treblinka, na Polônia; ou Ravensbrück e Sachsenhausen, na Alemanha; Espacio Memoria y Derechos Humanos Ex-Esma, na Argentina; Estádio Nacional, no Chile, recebem a cada ano cada vez mais visitantes interessados em saber mais sobre o que ocorreu ali e conhecer onde "a história aconteceu".

Nessa perspectiva, o presente dossiê pretende apresentar um panorama da problemática relacionada aos lugares de memória e de consciência das ditaduras na América Latina, contribuindo para o fortalecimento de um debate importante no âmbito da historiografia contemporânea. Acreditamos que os artigos aqui apresentados possibilitarão aos leitores o contato com distintas abordagens sobre a temática, destacando a amplitude do conceito de "lugares de memória", que não se restringem apenas aos espaços diretamente associados às práticas de violência e tortura que marcaram a estrutura e funcionamento dessas ditaduras no século XX. Além de apresentar reflexões sobre a diversidade desses lugares e distintos estudos de caso, outra contribuição desse dossiê é também destacar espaços e regiões pouco explorados pela historiografia relacionada ao tema no Brasil.

Nesse sentido, o dossiê se inicia com o artigo de Maura Leal da Silva e Janaína Valéria Pinto Camilo, intitulado "A Fortaleza de São José de Macapá: nos rastros das memórias, das prisões e torturas (1964-1973)”. No texto, as autoras analisam como essa fortaleza uma construção militar do século XVIII, hoje tombada como Patrimônio Histórico Nacional - se tornou, durante a ditadura civil-militar brasileira, um dos principais centros de detenção e tortura de presos políticos em Macapá, capital do Amapá. A partir do Relatório Final e dos depoimentos coletados pela Comissão Estadual da Verdade do Amapá (CEV-AP), criada em 2013 e cujos trabalhos foram concluídos em 2017, o artigo destaca as prisões ilegais, as torturas físicas e psicológicas, as arbitrariedades e a violência praticadas nas dependências da Fortaleza de São José de Macapá e o reconhecimento institucional desse espaço amapaense como um lugar de memória da ditadura, contribuindo para os estudos sobre a ditadura brasileira fora do eixo Sul-Sudeste, bastante privilegiado nas pesquisas sobre o tema.

As políticas públicas de memória no Brasil e as lutas políticas e sociais para a identificação e reconhecimento dos lugares de memória da ditadura são o tema do artigo "Lugares 
de memória da ditadura: disputas e agenciamentos nos processos de construção do ${ }^{\circ} \mathrm{BIB}$ Barra Mansa-Rio de Janeiro e da Casa Marighella-Salvador", escrito por Alejandra Magalhães Estevez e Priscila de Almeida Cabral. Também contemplando espaços territoriais pouco explorados pela historiografia especializada no tema, as autoras analisam a trajetória de lutas para a efetivação de dois lugares de memória: o antigo $1^{\circ}$ Batalhão de Infantaria Blindada do Exército, na cidade de Barra Mansa no sul fluminense, e a Casa Marighella, em Salvador, capital baiana. Nesse sentido, o artigo não só destaca os conflitos sociais, as negociações e os embates políticos envolvidos nesses processos ainda em aberto, mas também amplia as discussões sobre os lugares de memória, que não se limitam aos espaços associados diretamente às práticas de violações aos direitos humanos pela ditadura, mas contemplam também espaços associados às ações de militância política daqueles que, de distintas formas, resistiram à ditadura.

Além das dependências oficiais ou civis, utilizadas pelos órgãos de repressão, e das residências de militantes históricos que combateram as ditaduras, outros espaços, menos explorados pela historiografia, também merecem destaque entre os lugares de memória da ditadura, como os estádios de futebol, que, além de servirem como prisão para opositores políticos (como o Estádio Nacional, em Santiago no Chile, e o Caio Martins, em Niterói no Brasil), também foram utilizados, no Brasil, como instrumentos de construção de legitimidade por políticos ligados à ditadura, como destacam João Manuel Casquinha Malaia e Rafael Fortes Soares, em seu artigo "Brasil grande, estádios gigantescos: Toponímia dos estádios públicos da ditadura civil-militar brasileira e os discursos de reconciliação”. No texto, os autores analisam a construção de 14 estádios públicos estaduais com capacidade para mais de 40 mil pessoas, inaugurados entre 1964 e 1985, em sua maioria, com nomes dos governadores da Aliança Renovadora Nacional (Arena), partido de apoio à ditadura. Nessa perspectiva, o artigo debate como a nomeação, as disputas sobre as homenagens prestadas e a manutenção de nomes ligados à ditadura em espaços que se tornaram lugares de afeto de milhares de pessoas estão inseridas no complexo processo de (re)construção das memórias coletivas acerca da ditadura brasileira.

As disputas de memórias relacionadas aos lugares e às efemérides referentes ao período da ditadura civil-militar brasileira são o eixo condutor do artigo de Andréa Cristina de Barros Queiroz, “As memórias em disputa sobre a ditadura civil-militar na UFRJ: lugares de memória, sujeitos e comemorações”, que privilegia a trajetória da Universidade Federal do Rio de Janeiro (UFRJ), destacando como os espaços universitários também foram atravessados pela cultura política autoritária do regime. No texto, a autora analisa como essa centenária universidade, no contexto da modernização autoritária promovida pela ditadura brasileira, foi palco de censura, perseguição política e expulsão de alunos, funcionários e 
professores e de ações violentas das forças policiais, como no episódio da invasão, em 1966, da Faculdade Nacional de Medicina (FNM), na Praia Vermelha, cujo prédio histórico foi demolido em 1975. O texto também debate a demolição deste prédio como uma política de esquecimento promovida pela ditadura, que incluiu negociações e colaborações de parte dos dirigentes da instituição e da parcela conservadora dos docentes e técnicos que apoiavam o regime autoritário, bem como as recentes iniciativas da universidade na investigação das violações de direitos humanos sofridas por sua comunidade acadêmica e sua reparação no âmbito institucional, através das ações da Comissão de Memória e Verdade (CMV) da UFRJ, criada em 2013.

Encerrando esse dossiê, o artigo "Reflexiones en torno a los sitios de memória em Uruguay: las demarcaciones del paisaje represivo”, de Luciana Scaraffuni, propõe uma análise sobre os debates e embates políticos e sociais acerca das demarcações dos lugares de memória da ditadura - lugares da repressão ou da resistência - na cidade de Montevidéu, capital uruguaia, a partir da promulgação da "Ley de Creación de Sitios de Memoria Histórica del Pasado Reciente", em 2018. No texto, a autora privilegia os debates sobre o antigo Cárcel de Punta Carretas, o histórico presídio de presos políticos no Uruguai que funcionou até 1986, sendo posteriormente demolido, abrindo espaço para a construção de um shopping center, o Punta Carretas Shopping, um dos mais badalados de Montevidéu. Até pouco tempo, não havia no local nenhuma demarcação que remetesse ao antigo presídio que ali funcionou e não era oficialmente reconhecido como um lugar de memória da ditadura no Uruguai. Somente em fevereiro de 2020 se colocou a pedra fundamental de um futuro memorial a ser construído na entrada do shopping em homenagem às centenas de presos políticos que por ali passaram. A autora ressalta que o processo de identificação, recuperação e ressignificação desses lugares é marcado pelo enfrentamento de diferentes setores da sociedade uruguaia e seus distintos interesses e concepções sobre uma cultura de memória ou de esquecimento acerca do recente passado autoritário do país.

Esperamos que esse dossiê colabore com o debate sobre o passado ditatorial em um momento em que vivemos um intenso debate revisionista e negacionista, assim como - em especial no caso brasileiro - incentive, e dialogue com, a recuperação e abertura de espaços, muitos dos quais já somamanos de disputas, como o prédio do Departamento de Ordem Política e Social (Dops) na rua da Relação, no centro do Rio de Janeiro, e reforce não só a importância dos estudos historiográficos sobre a ditadura, mas também o papel significativo que os lugares de memória e de consciência podem exercer no ensino da história das ditaduras na América Latina e em ações pedagógicas que promovam, principalmente junto às novas gerações, uma cultura democrática e de respeito aos direitos humanos. 


\section{Referências}

JELIN, Elizabeth. Los trabajos de la memoria. Colección Memorias de la Represión. Buenos Aires: Siglo XXI, 2002.

NORA, Pierre. Entre memória e história: a problemática dos lugares. Revista Projeto História (São Paulo). n. 10, p. 7-28, 1993.
TEKLIK, Joanna; MESNARD, Philippe. El viaje a Auschwitz: turismo de la memoria o turismo cultural? In: FLEURY, Béatrice; WALTER, Jacques (Comp.). Memorias de la piedra. Buenos Aires: Ejercitar la Memoria Editores, 2011, p. 99-116. 